\title{
ENTREVISTA COM DAVID MAYBURY-LEWIS
}

\section{Mariza Corrêa, Roberto Cardoso de Oliveira e Roque de Barros Laraia}

Roque Laraia - Eu começo esta entrevista perguntando ao Dr. David como ele chegou ao Brasil. É uma história que nós conhecemos um pouco, mas que gostaríamos de ouvir outra vez.

David Maybury-Lewis - Muito obrigado, Roque. Foi o professor [Herbert] Baldus o grande responsável pela minha vinda ao Brasil. Eu o conheci em Cambridge, Inglaterra, onde eu era um aluno naquela época que estava para se formar no fim do ano. Não tinha a mínima idéia do que ia fazer depois de me formar. Interessava-me um pouco por índios nas Américas. Tinha feito cursos a respeito deles, mas, como pesquisar os índios na América? Eu não era antropólogo, nem tinha diploma,

* 18 de outubro de 2001, $25^{\circ}$ Encontro Anual da Anpocs, entrevista com David Maybury-Lewis, professor da Universidade de Harvard. Entrevistadores: Mariza Corrêa (Unicamp), Roberto Cardoso de Oliveira (UnB) e Roque de Barros de Laraia (UnB/Anpocs). nada. E fui lá [ao Congresso dos Americanistas], perguntando aos professores de lá como é que um jovem que falava bem o espanhol podia ir estudar os índios nas Américas. Ninguém dava muita bola, o que era bem compreensível, a não ser o Baldus, que se animou: "Por que você vai para a América hispânica? Venha para o Brasil! Tem trabalho para uma vida inteira”. Eu falei: professor, eu falo espanhol, não falo nada de português... De maneira que eu nunca pensei na possibilidade de vir para o Brasil. Ele disse: "Se você fala o espanhol, pode aprender o português num instante. Venha para o Brasil, que eu ajudo você. Lá no Brasil, na fronteira com as Guianas, há tribos completamente desconhecidas, você poderia trabalhar lá! Você é inglês?" Sim, senhor! "Então você nem precisa entrar pelo Brasil, porque o governo brasileiro é muito complicado, vai criar dificuldades para um jovem aluno, sem doutorado, sem nada, que diz que vai estudar os índios. Mas você indo para a Guiana Britânica, pode atravessar a frontei- 
ra e trabalhar do lado brasileiro, sem papelada, sem passaporte, sem nada. É bem simples". Aí eu saí de lá pensando: é esse tipo de professor que eu quero, que acaba de me convidar para atravessar uma fronteira que eu nem consigo localizar no mapa, trabalhar entre tribos desconhecidas e ele fala que me ajuda a fazer ciência em cima desses dados. Foi assim que ele lançou a idéia e, no ano seguinte, quando ele não esperava - foi uma surpresa enorme para ele - eu apareci no escritório dele: bom, eu sou aquele que conversou com o senhor no Congresso dos Americanistas, lá em Cambridge, e eu estou aqui com um contrato na Cultura Inglesa para ensinar inglês e gostaria de estudar etnologia brasileira com o senhor. Foi assim que eu comecei, foi assim que vim para o Brasil.

Mariza Corrêa - Você foi, em seguida, aluno do Baldus na Escola de Sociologia e Política?

David Maybury-Lewis - Sim, na Escola de Sociologia e Política. Lá ele era meu professor de etnologia brasileira... Além de outros como Juarez Brandão Lopes, Oracy Nogueira... Quem mais?

Roberto Cardoso - Rubbo Muller.

David Maybury-Lewis - Rubo Muller também. Até alcancei o [Donald] Pierson.

Roque Laraia - Foi contemporâneo meu.

Mariza Corrêa - E você foi em seguida para o campo?

David Maybury-Lewis - Eu passei um ano e meio, se não me engano, em São Paulo, estudando etnologia brasileira. Depois eu fui para o campo com minha senhora, a Pia. Ela também freqüentava os seminários de Baldus, ele era muito democrata. Então, nós dois fomos para os Xerente e fizemos uma pesquisa de campo entre eles.

Roberto Cardoso- Isso foi em?

David Maybury-Lewis - De 1955 até 1956. Depois eu voltei para a Inglaterra, entrei para o Programa de Antropologia Social da Universidade de Oxford, fiz exames, aquela coisa toda. Depois saí de novo, mas desta vez com passaporte e papelada, tudo pronto para fazermos uma pesquisa entre os Xavante, que seria uma pesquisa para o meu doutorado.

Roque Laraia - Era certo que sua ida ao Xerente era para aprender a língua e poder chegar aos Xavante?

David Maybury-Lewis - Era. Esse foi o sistema, porque nosso interesse naquela época era o de fazer trabalhos de pesquisas entre tribos mais ou menos na fronteira, entre tribos menos afetadas pela nossa civilização.

Roberto Cardoso - Na fronteira de expansão, não na fronteira internacional.

David Maybury-Lewis - Isso, ainda bem que você explicou isso. Na fronteira de expansão. Então, estávamos muito interessados em trabalhar com grupos indígenas que realmente tinham o mínimo de contato com a chamada civilização ocidental. Todo mundo falava que o grupo mais indicado era o dos Xavante. Aí a gente se animou! O problema era como falar com eles? Nós íamos para os Xavante com as melhores intenções, mas como explicar que vínhamos com tão boas intenções, se não falávamos nada que eles pudessem entender? Então a solução era fazer uma pesquisa prévia entre os Xerente, que já falavam português, aprender a língua Xerente, e chegar até os Xavante rezando para que eles entendessem o meu Xerente.

Mariza Corrêa - Na segunda pesquisa você foi com a Pia e o seu filho?

David Maybury-Lewis - Sim, com os dois.

Mariza Corrêa - E como é que foi sua estadia com sua mulher e uma criança tão pequena?

David Maybury-Lewis - Você pode imaginar que saindo da Inglaterra, e saindo da Dinamarca, a terra da Pia, e com o filho, isso causou um escândalo na família. Os meus pais e os pais da Pia diziam: "Não, isso é uma loucura! Por que vocês vão fazer isso? Por que não deixam o filhinho aqui 
com a gente? E se este homem insiste, por que você não deixa a Pia aqui também? Você fica com o filho e este maluco pode ir lá fazer as suas pesquisas". Mas a Pia foi firme, ela falou: "Não, nós vamos juntos e a gente não vai deixar o filho um ano, talvez mais. Todo mundo vai junto".

Roberto Cardoso - Eu queria voltar um pouco à parte Xerente. Nós nos conhecemos exatamente nesta época, em 1955, você estava iniciando o seu trabalho e eu o meu. Mas uma coisa que sempre me deixou curioso foi o porquê de você não ter publicado a sua dissertação de mestrado. Você se tornou mestre pela Escola de Sociologia e Política, orientado pelo Baldus e esse trabalho nunca apareceu. E a minha pergunta, embora eu saiba que você tem o hábito de escrever e guardar na gaveta durante muito tempo para publicar depois - quer dizer, é muito cuidadoso com o seu próprio trabalho - eu pergunto se o seu cuidado com a dissertação de mestrado foi tão grande a ponto de nunca publicá-la ou você transformou a dissertação no livro sobre os Xerente que você acabou publicando. Ou não chegou a publicar?

David Maybury-Lewis - Não, eu não cheguei a publicar um livro a respeito dos Xerente. Eu realmente não publiquei a dissertação da Escola de Sociologia e Política porque eu a achei fraca. Ela era razoável e por meio dela consegui o grau de mestre. Mas não era uma coisa que eu ia publicar a não ser depois de trabalhá-la. E depois eu perdi o fio. Fui para os Xavante, estava publicando coisas sobre os Xavante... Mais tarde eu publiquei artigos sobre os Xerente, baseado nos dados que eu colecionei. Mas o livro sobre os Xerente eu estou devendo ainda...

Mariza Corrêa - Mas eu acho que os Xerente se saem melhor do que os Xavante em O selvagem e o inocente.

\section{David Maybury-Lewis - Será?}

Mariza Corrêa - A parte inicial, onde os Xerente aparecem, eu acho muito interessante. E O selvagem e o inocente foi publicado depois do seu trabalho de campo com os Xavante. E foi uma das pri- meiras publicações, como se diria hoje, reflexivas a respeito do trabalho de campo. Mas, já que o Roberto voltou atrás, eu queria voltar um pouquinho antes, sobre a sua origem familiar. Você é inglês, mas não nasceu na Inglaterra. Onde você nasceu?

David Maybury-Lewis - Isso é um problema, saber exatamente onde eu nasci. Eu nasci numa nação que não existia naquela época. Meu pai era engenheiro do Império Britânico e já que eu era o caçula da família - na época, o meu pai era um sênior, tinha o direito de se locomover de uma casa dos funcionários britânicos para outra com 24 camelos - a minha grande alegria de pequenininho era ficar brincando com os cameleiros. Os nossos empregados eram sofisticados, educados, falavam um bom urdu, mas as pessoas que mexiam com os camelos eram da região (sind), só falavam o sindi, não falavam nem urdu e eram os selvagens, por assim dizer. Os nossos empregados os consideravam selvagens, falavam que eu não deveria brincar com eles. Era a alteridade, foi o meu contato com a alteridade na infância. E é lógico, a única coisa que eu queria fazer na vida era brincar com eles. Eles brincavam comigo, eu vivia com os camelos. E cada vez que a gente se locomovia de um lugar para outro, eu via a procissão de camelos saindo de noite. Eu me lembro ainda dos cantos que eles cantavam, quando saíam com os camelos e a casa ficava vazia. No dia seguinte nós íamos de carro, evidentemente, e não de camelo, para a nova casa que estavam montando para nós. Isto tudo aconteceu na terra que hoje em dia é o Paquistão, que naquela época não existia como país.

Mariza Corrêa - E como você voltou ao Brasil, depois de defender o doutorado sobre os Xavante e como conheceu o professor Roberto Cardoso de Oliveira e começaram aquela história institucional tão bonita no Museu Nacional?

David Maybury-Lewis - Bom, eu conheci o Roberto Cardoso antes de voltar para fazer a pesquisa entre os Xavante. Nós nos conhecemos quando eu estava fazendo a pesquisa entre os Xerente, se não me engano. E depois eu fiz meus exames lá em 
Oxford, saí de lá com uma bolsa, um diploma... A bolsa era o negócio mais importante (risos).

Roque Laraia - Mas eu gostaria de perguntar por que você, tendo feito a graduação em Cambridge, foi fazer o doutorado em Oxford? Alguma razão especial?

David Maybury-Lewis - Razão de comodidade, porque naquele tempo a gente não tinha bolsa de estudo e a minha família morava em Oxford. Então, enquanto estudava, eu morava em casa com a família, com essas bolsas caseiras que todo mundo conhece (risos).

Mariza Corrêa - Aí você voltou para o Brasil outra vez com esta bolsa?

David Maybury-Lewis - Sim, com esta bolsa.

Mariza Corrêa - E daí...?

David Maybury-Lewis - Daí eu voltei, acho que para o Rio...

Roberto Cardoso - Sim, foi para o Rio mesmo, para o Museu do Índio.

David Maybury-Lewis - Voltei para o Rio mesmo e fiquei o tempo necessário para preparar a viagem para os Xavante, para obter autorização e passagem num avião da FAB para levar a gente até lá. Fomos num pequeno Beechcraft - os oficiais da FAB foram muito simpáticos por sinal -, nunca esqueço a nossa primeira chegada aos Xavante: vimos as aldeias Xavante realmente como as aldeias dos cenários antigos dos cronistas do Brasil Central... Depois o capitão pousou o avião isso eu também nunca esqueço - e falou: "Vamos sair daqui antes que os Xavante cheguem"! Podíamos ver os Xavante correndo e chegando perto e o pessoal do avião... eles pegaram os nossos "trens", jogaram e saíram. E nós ficamos lá, vendo o avião saindo e os Xavante chegando, sentindonos muito sós... assim na solidão do Brasil Central. Aí chegaram os Xavante e eu falei para eles alguma coisa como Are... Are kto... Aí fiquei rezando: tomara que me entendam. Aí foi uma de- lícia, todos os Xavante começaram a dar risadas, a dar gargalhadas!

Mariza Corrêa - Por quê?

David Maybury-Lewis - Primeiro, porque eles entendiam. Nunca esperaram que uma pessoa que caíra do céu pudesse falar alguma coisa inteligível. E, depois, eu falava de uma maneira esquisita. Não era bem Xavante, era Xerente falado por um inglês com sotaque. Mas aí eles nos levaram para a aldeia. A Pia se acostumou instantaneamente à vida da aldeia. E o nosso filhinho também costumava brincar com as outras crianças. A única pessoa que não tinha função na aldeia, não podia fazer nada, não podia nem caçar, nem seguir os rastros de outros caçadores era eu. Eles entenderam que eu era como uma criança que podia se perder. Quando a gente ia para a mata eles ficavam de olho para não me perder. À noite os homens maduros tinham reuniões, e, nessas primeiras semanas de pesquisa, quando todos estavam caindo no chão de tanto dar gargalhadas, eu sabia que eles estavam contando as últimas burrices que eu tinha cometido durante o dia. Eu fiquei como uma espécie de televisão para os índios, eu era o palhaço!

Mariza Corrêa - Depois você voltou para a Inglaterra.

David Maybury-Lewis - Voltei para a Inglaterra, fiz o meu doutorado, arrumei meu primeiro emprego, e também meu último emprego, nos Estados Unidos, no Departamento de Antropologia de Harvard. E depois entrei em contato com meu amigo Roberto Cardoso para montarmos esse projeto Harvard-Brasil Central. A idéia de montar o PPGAS do Museu Nacional foi do Roberto Cardoso. E eu voltei para ampliar minhas pesquisas entre os Xerente e os Xavante. Revisitei essas tribos. Mas também para montar essa pesquisa em conjunto com os colegas brasileiros e os alunos de pós-graduação de Harvard.

Roberto Cardoso - Isso foi em 1962 mais ou menos.

Mariza Corrêa - E quem financiava o projeto Harvard-Brasil Central? 
David Maybury-Lewis - Nos Estados Unidos, a gente tinha o financiamento do National Institute of Health, que naquele tempo dava muito dinheiro para a pesquisa básica nas Ciências Sociais. A pesquisa tinha de ter alguma coisa a ver com a área de saúde, mas a relação podia ser bastante teórica.

Roberto Cardoso - Seria interessante, a essa altura, você contar um pouco sobre a guinada que você deu dos estudos clássicos que fazia, inspirado na tradição inglesa, de monografias, de descrições das sistemáticas de cada cultura, de cada sociedade indígena, para os estudos de contato, de questões de ação, de prática, e dos problemas teóricos emergentes. Isso tem alguma ligação com a criação do Cultural Survival do qual você é presidente e que está em Harvard? Qual é a ligação, em que momento você decidiu direcionar sua atividade de pesquisa assim?

David Maybury-Lewis - Isso foi depois das primeiras pesquisas, que foram no estilo clássico, a respeito da estrutura social dos povos indígenas do Brasil Central, pesquisa a respeito das idéias deles, da organização dualista deles etc. etc. Mas aí, naquela época, o Brasil estava sendo acusado de genocídio e nós, evidentemente, tomamos conhecimento disso. E depois, através das minhas leituras, descobri que não era só no Brasil que isso acontecia, era um fenômeno mundial que a fronteira de expansão estava produzindo, que invasores estavam entrando em terras indígenas e matando os índios que resistiam. Ficamos revoltados e muito chocados com isso. Aí eu voltei e conversei com o pessoal da Associação Americana de Antropologia. "Bom, isso é um problema mundial e dentro da Antropologia, será que não poderíamos tentar fazer alguma coisa para aliviar essas situações?" Aí os meus amigos falavam: "Sim, mas o que a gente pode fazer? Há interesses extremamente poderosos esmagando essas sociedades indígenas. Nós não temos condições de combater esses interesses. O que podemos fazer é escrever livros. Esse é o nosso métier". Mas aí eu não aceitei isso, e mais ainda, a minha senhora, a Pia, não aceitou. Ela falou: "Não, isso não é possível, tem que ter alguma coisa que a gente possa fazer, te- mos o dever moral de fazê-lo". Por isso fundamos a nossa ONG chamada Cultural Survival. Sua finalidade era realmente documentar os abusos, publicar documentos a respeito e verificar a possibilidade de aliviá-los. Essa finalidade continua até hoje.

Roque Laraia - Eu gostaria de voltar um pouco ao início dos anos de 1960, ao projeto Harvard-Brasil Central. Gostaria que você falasse um pouco sobre o grupo de antropólogos, com os quais eu até tive o grande prazer de conviver, que fizeram parte do projeto, tanto os antropólogos americanos quanto os nossos colegas brasileiros.

David Maybury-Lewis - Realmente esse grupo foi extremamente importante na minha vida e, espero, na antropologia brasileira também. Todos os integrantes colaboravam com o projeto Brasil Central que era em Harvard e no Museu Nacional. O projeto foi liderado no Brasil pelo Roberto Cardoso e incoporou, do lado brasileiro, Roberto da Matta, Julio César Melatti e Roque Laraia. Eu me lembro que o Roque esteve conosco entre os Xerente uma vez, fazendo pesquisa conosco. Dos Estados Unidos participaram Terence Turner e sua esposa, Joan Bamberg, Jean Carter e Christopher Crocker, que fez um grande livro sobre os Bororo.

Roberto Cardoso - E Dolores Newton também.

David Maybury-Lewis - Isso, Dolores Newton também, obrigado.

Roque Laraia - Eu apenas trabalhei com a sociedade brasileira de Tocantins, que era a frente pioneira que entrava em contato com os Xerente. Era uma coisa interessante, porque a oposição entre índios e brancos era tão forte que o David Maybury-Lewis não podia fazer trabalhos junto à comunidade brasileira, e eu não podia também aparecer à comunidade como alguém que estudasse índios. Só nos encontramos no final do trabalho, quando tudo já estava feito. A conjuntura do contato era uma área de muito conflito.

Roberto Cardoso - Eu queira acrescentar que paralelamente ao trabalho que o David executava 
com o grupo dele com as populações Jê, nós tínhamos um programa de contato interétnico, do qual o Roque participava, o DaMatta também, o Melatti. Então, foi uma articulação de dois projetos que ocorreram ao mesmo tempo.

Mariza Corrêa - Como se deu essa articulação entre suas preocupações mais teóricas e sua atuação prática?

Roberto Cardoso - O tema das relações interétnicas representava interesses que foram mais ou menos consolidados, creio, não sei se você concorda, institucionalmente com a criação do Cultural Survival. Isso foi o que fez com que você mais se aplicasse a fazer um tipo de trabalho diferente.

David Maybury-Lewis - É, realmente. E isso tem criado uma espécie de tensão na minha vida acadêmica. Porque eu gostava e ainda continuo gostando de fazer as duas coisas, o trabalho teórico e o trabalho prático. Eu acho que as duas tendências são extremamente importantes na antropologia e a gente não pode escolher uma e negligenciar a outra, mas é bem possível que a mesma pessoa, ou um mesmo antropólogo, só seja capaz de trabalhar numa tendência, ou pelo menos numa das tendências agora, deixando a outra para mais tarde. Eu sempre tentei fazer as duas coisas e isso causou, continua causando, tensão na minha vida acadêmica. Porque sempre que eu estou trabalhando nesse livro, eu poderia fazer outra coisa. Atualmente, acabo de editar um livro chamado The politics of ethnicity: indigenous peoples in Latin American States. Deu muito trabalho, reuniu artigos sobre México, Guatemala, Panamá, Colômbia, Equador, Peru, Bolívia e Brasil. Evidentemente sobre o Brasil eu fiz o artigo. Também estou trabalhando num livro maior agora chamado The Indian question in the Americas. Mas, fazendo isso, eu tive de deixar de lado as minhas pesquisas Jê. Eu tenho uma espécie de fila de espera nas gavetas de meu gabinete. Eu quero a todo custo voltar às coisas Jê que eu ainda tenho para publicar. Publicar também mais coisas a respeito da organização dualista Jê. E também, se Deus quiser, eu quero voltar e publicar o livro que devo a respeito dos Xerente.
Roque Laraia - Eu gostaria de saber a respeito de uma experiência muito interessante que você teve - produção de uma série de TV, Millennium, que foi divulgada praticamente no mundo todo. No Brasil, a gente teve a oportunidade de assistir. Acho muito interessante porque atingiu um público muito maior do que o público acadêmico, que geralmente é o nosso público.

David Maybury-Lewis - Realmente, mas essa experiência aumentou a tensão na minha vida porque levou anos para fazer esse seriado de televisão. Eu só topei a parada porque simpatizei muito com um jovem canadense que tinha estudado comigo em Harvard. Ele se interessava por fazer filmes e sugeriu o seriado; então eu achei bom. Achei uma ótima idéia. Mas eu nunca acreditei que ia acontecer, porque quando eles falaram que ia custar pelo menos um milhão de dólares cada programa, eu nunca imaginei que pudessem arrecadar tanto dinheiro. Então, eu me acostumei a ficar nos coquetéis, falando para meus amigos: "Sim, sim, eu estou pensando em fazer um seriado de TV". Eles diziam: "Você é louco, completamente louco; você sabe o que vai acontecer com você? Você vai ser envolvido por megalomaníacos, tudo o que você quiser fazer eles vão distorcer quando chegar na tela. É uma loucura, você não deve pensar nisso". Mas eu fiquei pensando: "Isso não acontece, de qualquer maneira não vai se realizar". Um belo dia, pelo telefone, alguém diz: "Já temos o dinheiro, vamos começar logo! Você pode sair de Harvard no mês que vem?" Eu disse: "Não, espera aí, na vida acadêmica não é assim que a gente faz. No fim do semestre talvez eu consiga autorização para sair. Depois aprendi a minha primeira lição de fazer filmes: me convidaram para sair imediatamente, mas depois de três, quatro meses não tinha acontecido nada, nada ainda. Foi bom não ter saído logo, correndo.

Mariza Corrêa - Quantos países vocês percorreram?

David Maybury-Lewis - Doze países diferentes. Eu também achava, no início, que ia visitar todos os países e fazer comentários sobre todos os países. Fiquei um pouco triste quando soube que não era 
assim que íamos fazer o seriado. Tínhamos equipes de filmagem em vários lugares ao mesmo tempo e eu só podia estar em um lugar. Mas depois que eu tive a experiência de filmar, fiquei tão feliz de não Ter de visitar todos os países, porque fazer filmes é o negócio mais chato que eu já experimentei na minha vida. A gente acorda cedo - porque todos os cineastas adoram a luz da madrugada - às 3, às 4, vai para pegar a luz e fica lá esperando duas, três, quatro, cinco horas... e assim por diante.

Mariza Corrêa - Você foi a algum país do Leste nessa pesquisa?

David Maybury-Lewis - Sim, fomos para a Indonésia, para a Austrália e para o Nepal, num programa muito interessante chamado "Strange Relations", relacionamentos curiosos. Isso era para mostrar para o grande público como é que a família funciona quando o homem pode ter várias mulheres ao mesmo tempo e quando a mulher pode ter vários homens simultaneamente. O interessante nesse programa eram dois episódios, que foram realmente histórias de amor dentro desse tipo de estrutura familiar. Geralmente nós temos a tendência de pensar que só entre duas pessoas nasce o verdadeiro amor, não é possível quando se tem várias mulheres estar realmente apaixonado por uma delas. E muito menos a mulher que tem vários homens. A história da mulher era uma tragédia. Uma mulher extremamente simpática, muito linda a meu ver, que se casou com um jovem e ele a levou para sua família e, na tradição daquela região do Nepal, eles esperavam que ela se casasse com todos os quatro irmãos. Querendo ser uma mulher tradicional, o centro da família, ela se esforçava para tratar a todos os irmãos em pé de igualdade. O que aconteceu? Aconteceu que o seu marido, o primeiro, a sua paixão, ficou com ciúmes dos seus próprios irmãos. Ficou pensando que ele deveria sair da aldeia, ir para a cidade e criar uma outra vida para ele. E lá ficou ela, sofrendo, chorando, coitada. Cada vez que vejo esse filme, eu choro.

Roberto Cardoso - Eu acho que há evidentemente um interesse permanente em saber qual o pa- pel de um pesquisador, um antropólogo como você, que veio ao Brasil fazer suas pesquisas, primeiro, ligado ao mestrado e, depois, ao doutorado, e ficou conosco todos esses anos. Como você mesmo avalia os resultados que as pesquisas podem ter atingido não só em relação à expansão dos estudos Jê, mas à própria pesquisa etnográfica no Brasil? Evidentemente, é claro que todos reconhecemos a sua importância, mas é bom ouvir isso de você.

David Maybury-Lewis - Bom, isso me deixa numa situação delicada, porque não cabe a mim realmente falar do que eu pude contribuir para a etnologia brasileira. Isso é uma pergunta para vocês. Mas o que eu espero que a gente tenha conseguido é estabelecer o padrão do etnólogo e da etnologia brasileira. Eu sei que essa sempre foi uma preocupação sua. Eu acompanhei essa preocupação e fico extremamente feliz quando penso no fortalecimento da etnologia e da antropologia brasileira. Sem dúvida, o Brasil é um dos países onde hoje em dia há uma tradição muito forte de boa antropologia. Não é somente nas Américas que as pessoas pensam assim, o Brasil é um lugar onde se faz antropologia séria, onde seria bom ir estudar. Os meus alunos já pensam nesses termos. Eles já estão trabalhando no Peru, na Bolívia, mas gostariam de fazer um estágio aqui, porque sabem que a antropologia no Brasil é séria. Na medida em que eu tenha podido contribuir para esse desenvolvimento, fico muito feliz.

Roque Laraia - Gostaria de acrescentar que sua influência na antropologia brasileira deveu-se também ao fato de que alguns antropólogos americanos, que não da Universidade de Harvard, mas que chegaram a fazer estágio nesta Universidade,vieram estudar no Brasil influenciados por suas pesquisas. Eu gostaria de citar David Price, Helen Basso e outras pessoas, cujos nomes agora não lembro, mas que vieram influenciadas pelo projeto. Alguns deles, como o Price e a Helen, passaram pelo menos um semestre em Harvard, mas parece que existem outras pessoas também.

Mariza Corrêa - Quais você acha que foram as principais conseqüências teóricas das pesquisas 
com os grupos Jê? E você acredita que essas conseqüências ainda se mantêm hoje?

David Maybury-Lewis - Bom, as conseqüências teóricas foram, ao meu ver, uma crítica desenvolvida ao estruturalismo de Lévi-Strauss. Uma crítica, eu espero, generosa, porque Lévi-Strauss teve uma contribuição bastante grande. Mas a crítica teve de ser feita e com isso entramos numa outra linha de comparação no Brasil Central. Eu acho que os estudos do Brasil Central, de uma maneira geral, avançaram muito com isso. Porque antigamente, quando começamos essas pesquisas, tínhamos etnografias dessa tribo, da outra tribo, daquela tribo, mas, depois de vários anos, tínhamos idéias teóricas desenvolvidas por meio das comparações feitas no Brasil Central. E também eu fiquei muito feliz de ver como as novas gerações estão incorporando nossos resultados do Brasil Central em outras comparações desenvolvidas pelo país inteiro. De maneira que uma das conquistas dos nossos esforços foi o desenvolvimento de uma verdadeira antropologia teórica comparada.

Mariza Corrêa - Em que medida você acha que a etnologia contemporânea tem algum diálogo com as conseqüências das pesquisas feitas por você no Brasil Central?

David Maybury-Lewis - Eu acho que esse diálogo ainda está no início e é uma coisa que deve ser fortalecida. O Roberto falou, e com razão, sobre as coisas que eu mantenho engavetadas, mas eu tenho um artigo chamado "Teorias indígenas, idéias antropológicas" que entra realmente nesse ponto. Aliás, é uma linha de pensamento paralela ao pensamento de Eduardo Viveiros de Castro.

Roque Laraia - Até onde o trabalho de Curt Nimuendaju influenciou no desenvolvimento do trabalho do Brasil Central?

David Maybury-Lewis - Bom, no início todo o nosso trabalho estava baseado no dele. Nimuendaju foi o grande pioneiro nessa região, e reconhecido como tal. Eu acho que seus trabalhos são excelentes levando em consideração a época. De maneira que ele foi o herói fundador de tudo isso.
Roberto Cardoso - Mas eu acho que a problemática teórica aparece mais com o Lévi-Strauss...

David Maybury-Lewis - Realmente. Eu estava treinado para fazer as críticas estruturalistas. Então eu comecei a fazer uma crítica bastante extensa ao trabalho de Lévi-Strauss, mas felizmente eu parei. Fiquei pensando: "Mas por que eu estou fazendo isso? É uma crítica tão detalhada que deixa de ser generosa, e eu não quero fazer isso". Então, eu nunca publiquei a crítica. Engavetei e parti para outra. Ela vai sair num livrinho. Eu quero fazer um livrinho desse artigo sobre teorias indígenas. Mas aí, voltamos para a tensão na minha vida: se eu quero fazer isso, então, quando vou ter tempo de fazer outro livro ao mesmo tempo? É o drama da minha vida.

Mariza Corrêa - Eu acho que a gente não pode deixar de falar sobre o momento em que vivemos atualmente. Acho que o fato de você ter nascido no Paquistão acrescenta alguma coisa até de comovente na palestra de hoje de manhã. Gostaria, então, que você repetisse o final das coisas que você disse sobre a antropologia numa época de confusão. É importante deixar registrado porque é um momento histórico particular.

David Maybury-Lewis - Realmente, é um momento histórico para todos nós. Ora, o fato de eu ter nascido naquela área que hoje é o Paquistão, eu acho que tem pouca coisa a ver, isso é uma curiosidade, uma coincidência. Mas, realmente, o que eu estava querendo dizer nos parágrafos finais da palestra de hoje é que a antropologia sempre cultivou uma metodologia extremamente útil em situações confusas como esta que estamos vivendo atualmente. A antropologia, sobretudo pelo seu apego em entender as categorias que as pessoas usam para fazer sentido da vida, é uma grande contribuição. E parece que o mundo enlouqueceu mesmo. Em toda parte você encontra pessoas tentando dar sentido a essa loucura. É neste esforço que a antropologia é tão valiosa. Os antropólogos estudam as idéias que as pessoas usam para dar sentido aos outros, à alteridade, assim como à sua própria situação. Este dilema - de como dar sen- 
tido ao mundo e às situações tanto individuais quanto grupais - é a matéria principal da antropologia. Se os antropólogos continuarem desenvolvendo esta linha de pesquisa, poderão, a meu ver, contribuir em muito para a desmistificação de nosso mundo, que parece emaranhado em confusões.

Roque Laraia - Gostaríamos de agradecer ao David por esta entrevista.

\section{BIBLIOGRAFIA}

MAYBURY-LEWIS, David (ed.). (1979), Dialectical societies: The Jê and Bororo of Central Brazil. Cambridge, Harvard University Press.

(1984), A sociedade Xavante. Rio de Janeiro, Francisco Alves.

(1987), Indigenous peoples, ethnic groups and the State. Boston, Allyn and Bacon.

(1990), O selvagem e o inocente. Campinas, Editora da Unicamp.

(1992), Millennium: tribal wisdom and the modern world. Nova York, Viking.

MAYBURY-LEWIS, David \& ALMAGOR, Uri (eds.). (1989). Trought and society in the dualistic mode. Ann Arbor, University of Michigan Press. 


\section{ENTREVISTA COM}

\section{DAVID MAYBURY-LEWIS}

Mariza Corrêa, Roberto Cardoso de Oliveira e Roque de Barros Laraia

Nesta entrevista, o professor David Maybury-Lewis conta como o menino que adorava brincar com os "cameleiros" no Paquistão, onde nasceu, tornou-se um jovem pesquisador que iniciou sua carreira vivendo entre os índios Xavante e Xerente no Brasil das décadas de 1950 e 1960. Mesclando reminiscências pessoais às suas lembranças profissionais do tempo em que viveu no nosso país, Maybury-Lewis traça também um esboço da antropologia no Brasil nos últimos cinqüenta anos.

\section{INTERVIEW WITH MAYBURY-LEWIS}

Mariza Corrêa, Roberto Cardoso de Oliveira and Roque de Barros Laraia

In this interview professor David Maybury-Lewis recalls his fondness when playing with camel care keepers in Pakistan, where he was born, becoming, later on, a young researcher who stated up his career by living among the Xavante and Xerente Indians in Brazil in the 1950's and 1960's. Adding personal reminiscences to professional memories from the time he spent in this country, Mr. Maybury-Lewis also draws an outline of the Brazilian anthropology in the past fifty years.

\section{INTERVIEW AVEC DAVID MAYBURY-LEWIS}

Mariza Corrêa, Roberto Cardoso de Oliveira et Roque de Barros Laraia

Dans cette interview, le professeur David Maybury-Lewis raconte comment le petit garçon qui adorait jouer avec les "chameliers" au Pakistan, son lieu de naissance, est devenu un jeune chercheur qui commença sa carrière parmi les indiens Xavante et Xerente au Brésil entre 1950 et 1960. Maybury-Lewis, en associant des réminiscences personnelles à ses souvenirs professionnels de l'époque où il vécut dans notre pays, trace également une esquisse de l'anthropologie au Brésil au cours des dernières cinquante années. 